\title{
PERKUATAN TANAH DENGAN METODE SAND COMPACTION PILE PADA TANAH GAMBUT DAN ALUVIAL
}

\author{
Lea Karen Tanudjaya ${ }^{1}$ dan Chaidir Anwar Makarim² \\ ${ }^{1}$ Program Studi Sarjana Teknik Sipil, Universitas Tarumanagara, Jl. Letjen S. Parman No.1 Jakarta \\ lea.325150161@stu.untar.ac.id \\ ${ }^{2}$ Program Studi Sarjana Teknik Sipil, Universitas Tarumanagara, Jl. Letjen S. Parman No.1 Jakarta \\ Chaidir259@gmail.com
}

Masuk: 11-01-2021, revisi: 05-02-2021, diterima untuk diterbitkan: 17-02-2021

\begin{abstract}
Construction on the peat soil and alluvial soil will increase rapidly in the future, if we don't know the characteristics of the soil, construction problems and failures will occur. Peat soil and alluvial soil has a very low bearing capacity, so they have a very large settlement. Alluvial soil and any other sandy soils has a very low bearing capacity, just like peat soil, and sandy soil has a highly potential of liquefaction. This research is to find out whether Sand Compaction Pile method can improve the bearing capacity of the peat and alluvial soil, and prevent liquefaction in sandy soil. In this case study, we only focus to one bore hole that has a peat layer above the alluvial layer and then improve it with Sand Compaction Pile method. Comparing the bearing capacity results, before and after the improving, with Sand Compaction Pile method, we can find out whether the Sand Compaction Pile can be used for the soil improving method on the peat and alluvial soil.
\end{abstract}

Keywords: peat, alluvial, liquefaction, Sand Compaction Pile, bearing capacity.

\begin{abstract}
ABSTRAK
Pembangunan di atas tanah gambut dan tanah aluvial akan meningkat secara drastis kedepannya, apabila kita tidak mengetahui karakteristik dari tanah tersebut maka akan banyak masalah da/atau kegagalan konstruksi. Tanah gambut dan tanah aluvial memiliki daya dukung yang rendah sehingga akan mengakibatkan terjadinya penurunan yang besar. Tanah aluvial atau tanah berpasir lainnya juga memiliki daya dukung yang rendah dan kemungkinan potensi terjadinya likuefaksi sangat tinggi. Penelitian ini bertujuan untuk mengetahui apakah dengan metode Sand Compaction Pile (SCP) dapat memperbaiki parameter tanah, meningkatkan daya dukung dari tanah gambut dan tanah aluvial, dan mencegah potensi terjadinya likuefaksi pada tanah berpasir. Studi kasus ini lebih difokuskan terhadap salah satu bor log yang memiliki lapisan gambut yang tebal dan kemudian di perbaiki dengam metode Sand Compaction Pile. Dengan membandingkan hasil dari daya dukung tanah sebelum di perbaiki dan setelah di perbaiki dengan metode Sand Compaction Pile, kita dapat mengetahui apakah Sand Compaction Pile dapat di gunakan sebagai metode perbaikan tanah di tanah gambut dan tanah aluvial.
\end{abstract}

Kata kunci: gambut, aluvial, likuefaksi, Sand Compaction Pile, daya dukung.

\section{PENDAHULUAN}

Gedung, jembatan, jalan tol, bendungan, rumah, dan lain-lain merupakan hal yang akan dibutuhkan pada saat pemindahan Ibu Kota dari Jakarta ke Kalimantan. Akan tetapi kondisi tanah di daerah Kalimantan sebagian besar tidak mendukung bangunan yang akan di bangun, dikarenakan pulau Kalimantan merupakan daerah dengan lahan gambut terbesar kedua setelah Sumatera. Begitu juga dengan lahan aluvial, tidak hanya pada pulau Kalimantan tetapi lahan aluvial dapat kita jumpai di berbagai pulau di Indonesia. Dengan adanya lahan gambut dan lahan aluvial, dapat kita ketahui bahwa lahan tersebut mempunyai daya dukung (bearing capacity) yang sangat rendah sehingga para insinyur susah untuk menentukan perbaikan tanah atau perkuatan tanah apa yang akan di pakai. Pada kondisi seperti ini, metode Sand Compaction Pile (SCP) merupakan salah satu metode perbaikan tanah dalam hal daya dukung tanah dengan harga yang terjangkau. Dalam beberapa jenis penelitian (Hiroki Et Al. 2012) menunjukkan bahwa Sand Compaction Pile (SCP) dapat digunakan sebagai perbaikan pada tanah yang memiliki kadar air yang tinggi serta memiliki potensi likuefaksi. 
Tujuan dari penelitian ini adalah untuk mengetahui apakah dengan menerapkan metode perbaikan tanah Sand Compaction Pile dapat meningkatkan daya dukung tanah pada tanah gambut dan tanah aluvial dan mengetahui biaya yang dibutuhkan untuk membuat Sand Compaction Pile.

\section{Lapisan Aluvial}

Lapisan aluvial adalah salah satu jenis lapisan yang berasal dari proses endapan material - material yang terbawa oleh aliran air sungai (Munir, Moch. 2003). Tekstur dari lapisan aluvial ini tergantung dari energi pada aliran air yang berada di atas permukaan tanah. Jika aliran air di sungai tersebut deras dan cepat, maka akan menghasilkan jenis lapisan tanah dengan fragmen kerikil dan batu. Sebaliknya jika aliran air di sungai cenderung tidak terlalu deras dan lamban, maka akan menghasilkan jenis lapisan tanah dengan fragmen lumpur dan pasir.

Lapisan aluvial biasanya di temukan di daerah sekitaran pinggiran sungai. Akan tetapi berbeda dengan Pulau Kalimantan, lapisan aluvial tidak hanya terdapat pada pinggiran sungai, tetapi juga terdapat pada puluhan kilometer dari pinggiran sungai. Hal ini dikarenakan terdapat sungai purba pada daerah Pulau Kalimantan seperti gambar 1.

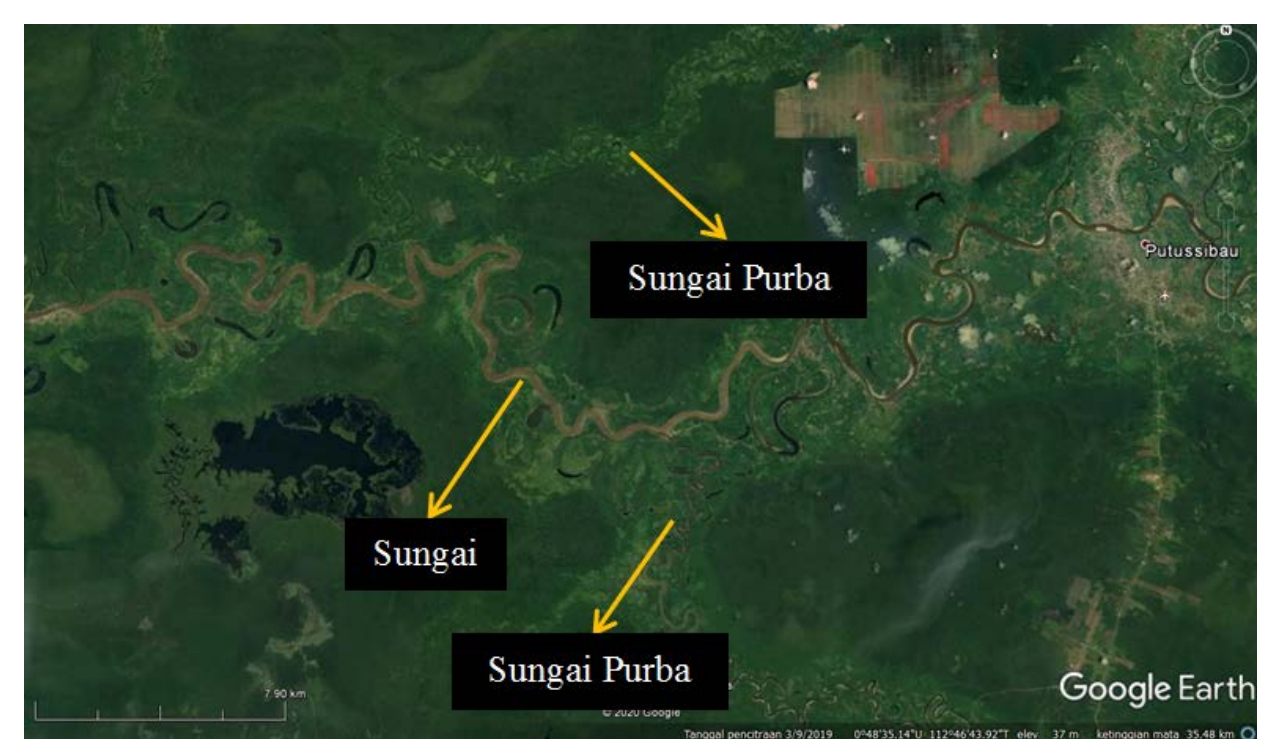

Gambar 1. Penampakan sungai purba melalui Google Earth

Hal ini merupakan salah satu penyebab kenapa lapisan alluvial terdapat pada daratan Pulau Kalimantan. Perbedaan sungai purba dengan sungai yang sekarang adalah sungai yang sekarang masih terdapat aliran air sedangkan sungai purba sudah tidak di aliri oleh air lagi sehingga menyebabkan lapisan alluvial dalam kondisi kering.

\section{Lahan Gambut}

Lahan gambut dapat diartikan sebagai lahan jenuh air, yang terbentuk dari endapan sisa - sisa jaringan tumbuhan dari masa lampau yang melapuk. Tanah gambut merupakan tanah lunak yang mempunyai daya dukung (bearing capacity) yang sangat rendah dan zat organik yang terbentuk secara alami yang berasal dari material tumbuhan. Gambut merupakan salah satu jenis tanah lunak yang terbentuk dari sisa - sisa tumbuhan yang membusuk seperti daun - daun, ranting - ranting, dan akar - akar pohon yang mati dan mengendap tanpa berdekomposisi selama bertahun - tahun sehingga memiliki serat dan kadar air yang tinggi.

\section{Daya Dukung Tanah}

Daya dukung tanah merupakan kemampuan tanah untuk memikul tekanan atau beban maksimum yang di berikan oleh berbagai jenis bangunan atau struktur, agar menghindari terjadinya keruntuhan geser (shear failure) dan penurunan berlebih pada pondasi. Perhitungan daya dukung tanah dapat dilakukan dengan teori Limit Equilibrium Method oleh Terzaghi (1948), Meyerhof (1963), Hansen (1970), dan Vesic (1973).

\section{Perbaikan Tanah}

Prinsip dasar dari perbaikan tanah adalah tanah yang kurang baik, dari segala sisi, dapat di perbaiki dengan melakukan peningkatan sifat - sifat dari tanah sesuai dengan tujuan yang diinginkan seperti peningkatan daya dukung dan kuat geser, lapisan tanah yang kedap air dan lapisan tanah dengan kapasitas infiltrasi yang besar. 
Tujuan umum dari perbaikan tanah adalah meningkatkan daya dukung tanah, meningkatkan kuat geser tanah, memperkecil kompresibilitas dan penurunan (settlement) tanah, memperkecil permeabilitas tanah, memperbesar permeabilitas tanah, memperkecil potensi kembang-susut pada tanah (swelling potential) dan menjamin kelestarian dan keberlanjutan sumberdaya alam dan lingkungan.

Adapun beberapa jenis perbaikan tanah yang sudah dikembangkan dan diketahui selama ini antara lain, perbaikan tanah dengan semen (soil cement), perbaikan tanah dengan kapur (soil lime), perbaikan tanah dengan abu (soil ash), perbaikan tanah dengan larutan kimia (solvent stabilization), perbaikan tanah dengan pemadatan, perbaikan tanah dengan konsolidasi, perbaikan tanah dengan teknik pengeringan (dewatering) dan perbaikan tanah dengan penggantian tanah (replacement).

\section{Sand Compaction Pile (SCP)}

Metode Sand Compaction Pile (SCP) dikembangkan pertama kali oleh Jepang pada tahun 1956. Sasaran dari metode Sand Compaction Pile (SCP) adalah tanah yang mempunyai daya dukung (bearing capacity) yang rendah seperti tanah berpasir (sandy soil) dan tanah lempung (clay soil) (Masaki, 2005). Cara bekerja metode Sand Compaction Pile (SCP) adalah dengan enginjeksikan pasir ke dalam tanah dan akan di padatkan menggunakan alat vibrator dengan menggunakan pipa sebagai casing agar pasir yang diinjeksikan tetap pada jalurnya dan membentuk sand pile (Michael Et Al. 1977), seperti gambar 2.

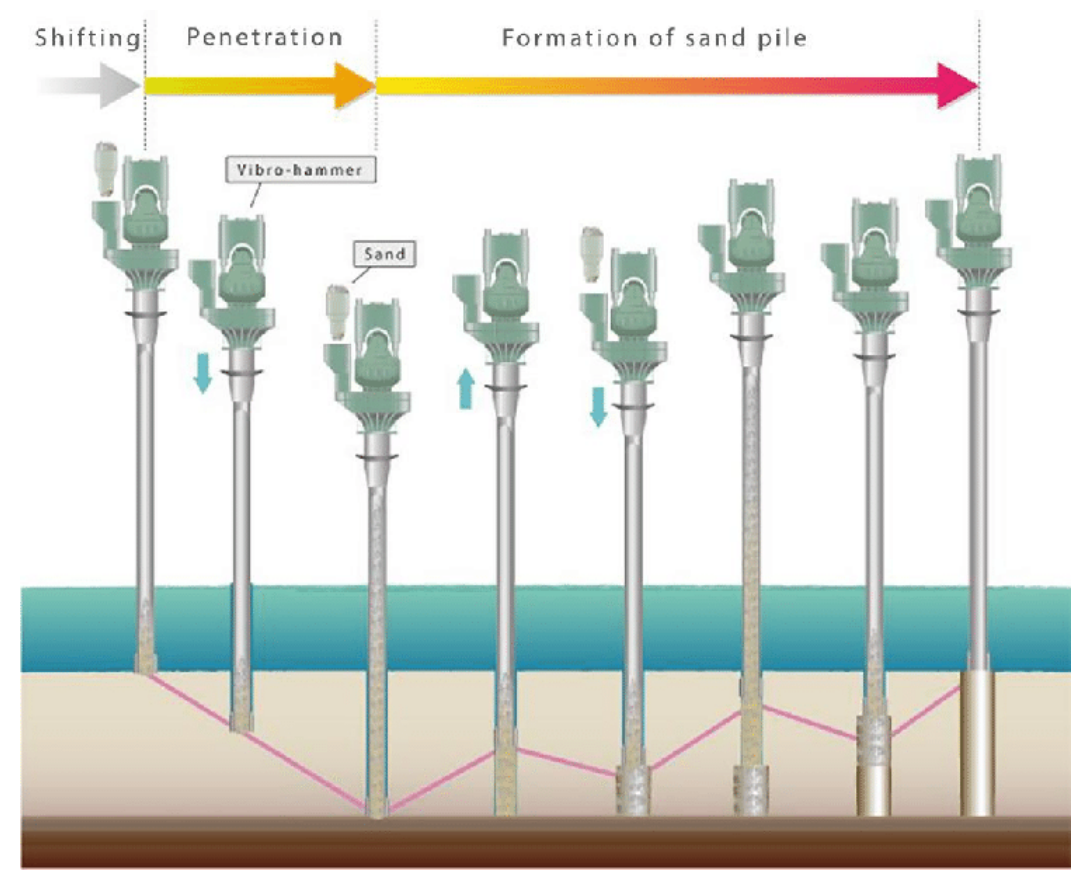

Gambar 2. Cara kerja alat Sand Compaction Pile.

\section{METODE PENELITIAN}

Metode penelitian yang dilakukan dalam beberapa tahap sebagai berikut:

1. Mengumpulkan data awal parameter dan teori - teori yang digunakan untuk melakukan analisis berupa buku buku dan jurnal.

2. Mengkorelasi kan data - data tanah yang ada dan menentukan parameter - parameter yang dibutuhkan.

3. Melakukan tes laboratorium untuk mengetahui kandungan mineral apa saja yang terdapat di dalam lapisan aluvial.

4. Melakukan tes apakah perkuatan tanah dengan metode Sand Compaction Pile dapat diterapkan pada lapisan aluvial dan lapisan gambut. 


\section{HASIL DAN PEMBAHASAN}

\section{Analisis Lapisan Aluvial}

Hasil dari analisis lapisan alluvial terdiri dari 3 sampel yang berbeda dengan sampel sebesar 3 kg. Analisis dilakukan dengan melakukan tes kandungan di laboratorium. Hasil laboratorium yang didapat seperti pada Tabel 1 dan Tabel 2.

Tabel 1. Hasil analisis laboratorium dari sampel 1

\begin{tabular}{|c|c|c|c|c|}
\hline No & Nama Mineral & Rumus Kimia & $\%$ & Keterangan \\
\hline 1 & Ilmenit & $\mathrm{FeTiO}_{3}$ & 2,36 & Berwarna merah metalik membulat tanggung \\
\hline 2 & Hematit & $\mathrm{Fe}_{2} \mathrm{O}_{3}$ & 0,23 & Berwarna merah, kusam, bentuk membulat tanggung \\
\hline 3 & Rutil & $\mathrm{TiO}_{2}$ & 1,78 & $\begin{array}{l}\text { Berwarna coklat kemerahan prismatik, membulat } \\
\text { tanggung }\end{array}$ \\
\hline 4 & Monasit & Tidak Terdeteksi & & \\
\hline 5 & Xenotime & Tidak Terdeteksi & & \\
\hline 6 & Kasiterit & Tidak Terdeteksi & & \\
\hline 7 & Turmalin & & 1,47 & $\begin{array}{l}\text { Berwarna hijau kecoklatan, prismatik }- \text { membulat } \\
\text { tanggung, transparan }\end{array}$ \\
\hline 8 & Kwarsa/gelas & $\mathrm{SiO}_{2}$ & 8,01 & $\begin{array}{l}\text { Berwarna putih, kuning, transparan dan bentuk bervariasi, } \\
\text { merupakan mineral ringan yang terbawa pada waktu } \\
\text { pendulangan }\end{array}$ \\
\hline 9 & Zirkon & $\mathrm{ZrSiO}_{4}$ & 86,15 & $\begin{array}{l}\text { Berwarna ros, putih, kuning kecoklatan, bentuk butir } \\
\text { prismatik, menyudut-membundar tanggung }\end{array}$ \\
\hline
\end{tabular}

Tabel 2. Hasil analisis laboratorium dari sampel 2

\begin{tabular}{|c|c|c|c|c|}
\hline No & Nama Mineral & Rumus Kimia & $\%$ & Keterangan \\
\hline 1 & Ilmenit & $\mathrm{FeTiO}_{3}$ & 0,81 & Berwarna merah metalik membulat tanggung \\
\hline 2 & Hematit & $\mathrm{Fe}_{2} \mathrm{O}_{3}$ & 0,12 & Berwarna merah, kusam, bentuk membulat tanggung \\
\hline 3 & Rutil & $\mathrm{TiO}_{2}$ & 0,98 & $\begin{array}{l}\text { Berwarna coklat kemerahan prismatik, membulat } \\
\text { tanggung }\end{array}$ \\
\hline 4 & Kwarsa/gelas & $\mathrm{SiO}_{2}$ & 4,17 & $\begin{array}{l}\text { Berwarna putih, kuning, transparan dan bentuk bervariasi, } \\
\text { merupakan mineral ringan yang terbawa pada waktu } \\
\text { pendulangan }\end{array}$ \\
\hline 5 & Turmalin & & 1,08 & $\begin{array}{l}\text { Berwarna hijau kecoklatan, prismatik }- \text { membulat } \\
\text { tanggung, transparan }\end{array}$ \\
\hline 6 & Monasit & Tidak Terdeteksi & & \\
\hline 7 & Xenotime & Tidak Terdeteksi & & \\
\hline 8 & Kasiterit & Tidak Terdeteksi & & \\
\hline 9 & Zirkon & $\mathrm{ZrSiO}_{4}$ & 92,84 & $\begin{array}{l}\text { Berwarna ros, putih, kuning kecoklatan, bentuk butir } \\
\text { prismatik, menyudut-membundar tanggung }\end{array}$ \\
\hline
\end{tabular}

\section{Analisis Hasil SPT}

Hasil analisis SPT pada tanah sebelum dan sesudah di perkuat oleh Sand Compaction Pile (SCP) yang dilakukan oleh Jepang. Dengan hasil analisis berikut diharapkan dapat di terapkan pada tanah gambut dan tanah aluvial di Indonesia. Hasil analisis yang di dapat seperti Gambar 3 dan Gambar 4. 


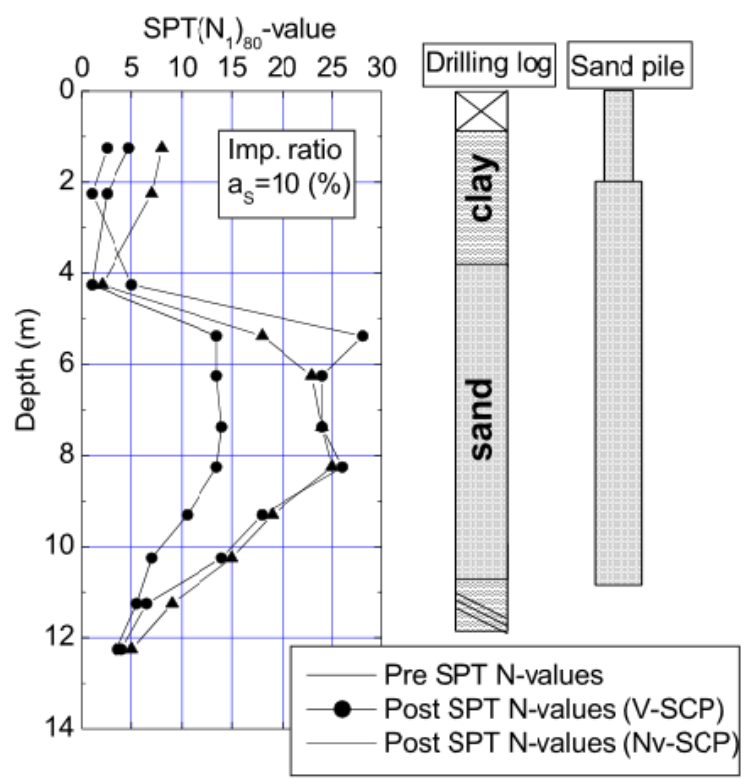

Gambar 3. Hasil N-SPT sebelum dan sesudah menggunakan perkuatan dengan metode Sand Compaction Pile

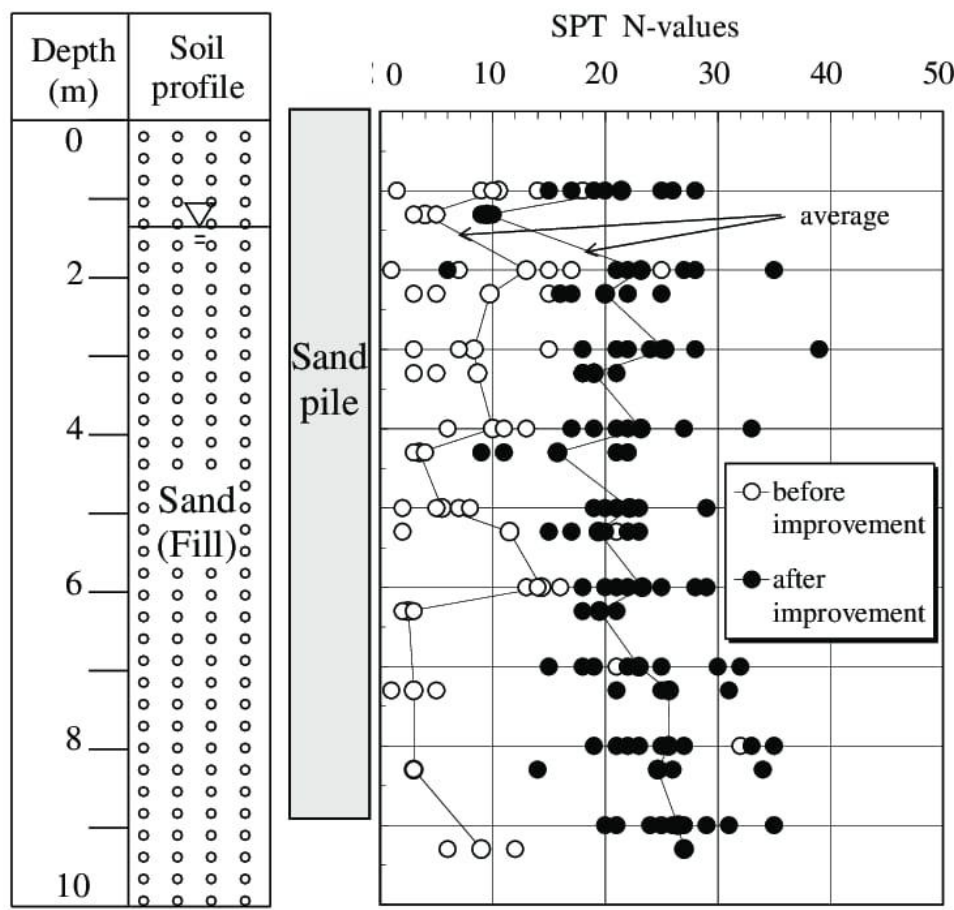

Gambar 4. Hasil N-SPT sebelum dan sesudah menggunakan metode Sand Compaction Pile pada tanah berpasir

Dari hasil tes di atas, dapat dilihat bahwa dengan menggunakan perkuatan tanah metode Sand Compaction Pile (SCP) dapat memperkuat keadaan tanah lunak dan meningkatkan daya dukung (bearing capacity) dari tanah lunak. Hal ini menjelaskan bahwa ketika di perkuat dengan metode Sand Compaction Pile (SCP) dengan teknik pemadatan, daerah di sekeliling sand pile juga ikut terpadatkan.

\section{Analisis Perbandingan Harga}

Perbandingan harga Sand Compaction Pile (SCP) dan Reinforced Concrete Pile (RCC), dengan data area sebesar $50 \mathrm{~m}^{2}$, dengan diameter SCP yang digunakan adalah 200 dan $250 \mathrm{~mm}$ dengan FM 1.5, dan diameter RCC yang digunakan adalah $500 \mathrm{~mm}$. Harga Sand Compaction Pile (SCP) menurun ketika diameter dari SCP dinaikkan dengan FM (Finess Modulus) yang tetap. Persentase perbandingan harga dari Sand Compaction Pile dan Reinforced Concrete Pile adalah $1.53 \%$ dan $1.3 \%$ seperti pada Tabel 3. 
Tabel 3. Perbandingan harga Sand Compaction Pile (SCP) dengan Reinforced Concrete Pile (RCC)

\begin{tabular}{cccc}
\hline $\begin{array}{c}\text { Diameter SCP (mm) } \\
\text { dengan FM }\end{array}$ & Diameter RCC (mm) & $\begin{array}{c}\text { Harga Rata-Rata SCP } \\
\text { (Rp) }\end{array}$ & Harga RCC (Rp) \\
\hline $200(1,5)$ & 500 & Rp 2,631,520 & Rp 172,282,325 \\
$250(1,5)$ & 500 & Rp 2,245,016 $172,282,325$ \\
\hline
\end{tabular}

\section{KESIMPULAN DAN SARAN}

\section{Kesimpulan}

1. Jenis - jenis mineral tanah jarang yang terdapat dalam lapisan alluvial adalah Ilmenit, Hematit, Rutil, Turmalin, Kwarsa/gelas, Zirkon, dan Monasit.

2. Persentase perbandingan harga Sand Compaction Pile (SCP) dan Reinforced Concrete Pile (RCC) adalah sebesar $1,53 \%$ dan $1,3 \%$

3. Perkuatan tanah dengan metode Sand Compaction Pile (SCP) dapat di terapkan pada tanah alluvial dan tanah gambut. Dari hasil lab yang sudah di jelaskan di atas membuktikan bahwa metode Sand Compaction Pile (SCP) dapat meningkatkan daya dukung (bearing capacity) dari tanah lunak.

\section{Saran}

Pada saat melakukan perbandingan harga, akan lebih baik jika di bandingkan dengan Stone Column, agar lebih terlihat perbedaan dari sisi daya dukung, mutu dan harga. Jika daya dukung dari Sand Compaction Pile masih kurang mendukung khususnya di tanah seperti di Kalimantan yaitu tanah gambut, dapat di tambahkan dengan konstruksi fondasi kayu.

\section{DAFTAR PUSTAKA}

Brinch Hansen, J. A. "Revised and Extended Formula for Bearing Capacity” Bulletin no. 28, Danish Geotechnical Institute Copenhagen, 1970, 5-11

Kinoshita, Hiroki, et al. "Sand Compaction Pile Technology and its Performance in both Sandy and Clayey Ground” International Symposium n Ground Improvement IS-GI Brussels, 2012.

Masaki, Kitasume. "The Sand Compaction Pile Method” United Kingdom: Taylor \& Francis, 2005.

Meyerhof, G.G. "Some Recent Research on the Bearing Capacity of Foundations" Canadian Geotechnical Journal, vol. 1, 1963, pp. 16-26.

Munir, Moch. “Geologi Lingkungan” Malang: Bayumedia Publishing, 2003.

Terzaghi, K, dan R.B. Peck. "Soil Mechanics in Engineering Practice” Wiley, New York, 1948.

Tomlinson, Michael, et al. "Pile Design and Construction Practice Sixth Edition” United Kingdom Taylor \& Francis, 1977.

Vesic, A. S. “Analysis of Ultimate Loads of Shallow Foundations” J. Soil Mech. Found, div. 99 (1), 1973, 45-76. 